Vol. 33, Issue 3, June 2006

Editorial

213 New Bioanalytical Technologies in Platelet Research and Diagnostics

Bugert, P. (Mannheim)

Obituary

215 In Memory of Our Honorary Member Prof. MUDr. Mikulás Hrubisko, Dr. Sc. Stangel, W. (Hannover)

Review Articles

217 Recent Advances in Platelet Transcriptomics Gnatenko, D.V.; Badou, W.F. (Stony Brook, NY)

227 Platelet Proteomics: Essentials for Understanding and Application

Moebius, J.; Zahedi, R.-P.; Sickmann, A. (Würzburg)

236 Towards the Identification of Novel Platelet Receptors: Comparing RNA and Proteome Approaches Bugert, P.; Ficht, M.; Klüter, H. (Mannheim)

244 Heterogeneity of Platelet Alloantigens and Alloantibodies: New Insights into Structure and Function

Socher, I.; Kroll, H.; Santoso, S. (Gießen)

254 The SASPA (Simultaneous Analysis of Specific Platelet Antibodies) Assay: Implementation and Performance in the Routine Laboratory Use

Nguyen, X.D.; Klüter, H. (Mannheim)

260 Red Blood Cell and Platelet Genotyping: From Current Practice to Future High-Throughput Donor Typing de Haas, M.; van der Schoot, E.; Beiboer, S.H.W.; Feskens, M.; Cheroutre, G.; Maaskant-van-Wijk, P.A. (Amsterdam)

\section{Band 33, Heft 3, Juni 2006}

Editorial

213 Neue bioanalytische Technologien in der Plättchenforschung und -diagnostik Bugert, P. (Mannheim)

Nachruf

215 Zum Tode unseres Ehrenmitglieds Prof. MUDr. Mikulás Hrubisko, Dr. Sc. Stangel, W. (Hannover)

Übersichtsarbeiten

217 Aktuelle Fortschritte in der Thrombozytentranskriptomik Gnatenko, D.V.; Badou, W.F. (Stony Brook, NY)

227 Thrombozyten-Proteomforschung: Grundlagen für das Verständnis und die Anwendung Moebius, J.; Zahedi, R.-P.; Sickmann, A. (Würzburg)

236 Identifizierung neuer Thrombozytenrezeptoren: Vergleich von RNA und Proteom-Ansätzen Bugert, P.; Ficht, M.; Klüter, H. (Mannheim)

244 Heterogenität von Plättchenalloantigenen und -alloantikörpern: Neue Einblicke in Struktur und Funktion

Socher, I.; Kroll, H.; Santoso, S. (Gießen)

254 Der SASPA(Simultaneous Analysis of Specific Platelet Antibodies)-Assay: Implementation und Durchführung in der täglichen Laborroutine

Nguyen, X.D.; Klüter, H. (Mannheim)

260 Erythrozyten- und Thrombozyten-Genotypisierung: Von der aktuellen Praxis zur zukünftigen Hochdurchsatz-Genotypsierung de Haas, M.; van der Schoot, E.; Beiboer, S.H.W.; Feskens, M.; Cheroutre, G.; Maaskant-van-Wijk, P.A. (Amsterdam) 


\section{Transfusion Medicine and Hemotherapy}

Vol. 33, Issue 3, June 2006

Original Articles

269 The ScanGel System Shows at least Equal Sensitivity for the Detection of Red Cell Antibodies in Comparison to the ID Micro Typing System

Kretschmer, V.; Schmidt, K.; Bornmann, M.; Karger, R. (Marburg)

274 Scansystem ${ }^{\mathrm{TM}}$ Enables Rapid and Sensitive Bacterial Detection in Platelets Stored in Additive Solution with Implementation of Standard Positive Control Capsules Schmidt, M.; Hourfar, M.K.; Heck, J.; Weis, C. (Frankfurt/M.); Montag, T.; Nicol, S.-B. (Langen); Seifried, E. (Franfurt/M.)

\section{Commentary}

279 Transfusion Medicine - Profile and Perspectives Hanfland, P. (Bonn)

285 Meetings and Conferences

273 Imprint

286 Guidelines for Authors

Forthcoming Papers are listed on page 288.

\section{Band 33, Heft 3, Juni 2006}

Originalarbeiten

269 Das ScanGel-System zeigt zumindest gleiche Sensitivität für den Nachweis von Erythrozyten-antikörpern wie das ID-Micro-Typing-System

Kretschmer, V.; Schmidt, K.; Bornmann, M.; Karger, R. (Marburg)

274 Scansystem ${ }^{\mathrm{TM}}$ ermöglicht einen schnellen und sensitiven Bakteriennachweis in Thrombozyten in Additivlösung sowie die Implementierung von Positivkontrollkapsel Schmidt, M.; Hourfar, M.K.; Heck, J.; Weis, C. (Frankfurt/M.); Montag, T.; Nicol, S.-B. (Langen); Seifried, E. (Franfurt/M.)

Kommentar

279 Transfusionsmedizin - Profil und Perspektiven Hanfland, P. (Bonn)

285 Tagungen und Kongresse

273 Impressum

286 Hinweise für Autoren

Einen Ausblick auf den Inhalt der kommenden Hefte finden Sie auf Seite 288. 